\title{
Microplastics Derived From Disposable Greenhouse Plastic Films and Irrigation Pipes: A Case Study From Turkey
}

Rezan Gündoğdu ( $\sim$ rezan.erdogmus@gmail.com )

Cukurova Universitesi Ziraat Fakultesi https://orcid.org/0000-0003-2501-9253

Derya Önder

Cukurova Universitesi Ziraat Fakultesi

Sedat Gündoğdu

Cukurova University: Cukurova Universitesi

Claire Gwinnett

Staffordshire University

\section{Research Article}

Keywords: Plasticulture, microplastic, drip irrigation, low tunnel greenhouse, terrestrial microplastics

Posted Date: February 24th, 2022

DOI: https://doi.org/10.21203/rs.3.rs-1282764/v1

License: (c) (i) This work is licensed under a Creative Commons Attribution 4.0 International License. Read Full License 


\section{Abstract}

Plastics are ubiquitous. It has been used in human activities, from agriculture to packaging, infrastructure, and health. The wide range of usage makes plastics an omnipresent pollutant in the environment. Microplastics (MPs) are one of the most concerning environmental problems. This study investigated the abundance and type of MPs in agricultural soil in the Adana/Karataş region in Turkey, where disposable low tunnel greenhouse plastic films and irrigation pipes were in use. For this purpose, one $\mathrm{kg}$ of soil samples from the top $5 \mathrm{~cm}$ (from the surface) was taken from 10 different sampling locations. An average of $11.13 \pm 2.31 \mathrm{MPs} / \mathrm{kg}$ of microplastic was found in the soil samples. The highest amount of microplastics was seen at the Bahçe-4 location with $32.0 \pm 14.36 \mathrm{MPs} / \mathrm{kg}$ and the lowest amount of microplastics at the Karataş-1 location with $0.3 \pm 0.3 \mathrm{MPs} / \mathrm{kg}$. The average size of microplastics was found to be $3.28 \pm 0.08 \mathrm{~mm}$. The average microplastics originating from greenhouse cover plastics was $3.29 \pm 0.09 \mathrm{~mm}$, and from disposable irrigation pipes was $3.17 \pm 0.22 \mathrm{~mm}$. It was determined that the amount of microplastics decreased in the soil where used plastics were removed after usage. As a result, it has been determined that a significant amount of microplastic pollution remains in soil due to plastics used in agricultural areas.

\section{Highlights}

- Soil samples were collected at 10 agricultural lands located

- Average microplastics were $11.13 \pm 2.31 \mathrm{MPs} / \mathrm{kg}$

- The mean size of microplastics was $3.28 \pm 0.08 \mathrm{~mm}$

- Almost two of three microplastics (87\%) were from greenhouse plastics

- Microplastic concentration was negatively correlated with the removal of plastics

\section{Introduction}

The production of plastic reached 368 million tons in 2019 due to its widespread use (PlasticEurope, 2020) In Europe, an average of 60 million tons of plastic is produced every year, and 27 million tons of this is stored as waste in landfills (WWF, 2018). As of the end of 2020, the total plastic production in Turkey was approximately 9.54 million tons, of which 8.4 million tons were consumed domestically (PAGEV, 2021). Excessive consumption of plastic also causes a significant amount of plastic waste. It is estimated that approximately 32 million tons of municipal waste were produced in Turkey in 2018, of which approximately $10 \%$ was plastic (Gündoğdu and Walker, 2021)

Plastic waste in the environment may undergo degradation and decomposition due to physical, chemical, and biological factors. Recent studies have revealed that many plastics, including plastics reported as biodegradable, break down into smaller fragments rather than decompose (Barnes et al., 2009; de Souza Machado et al., 2018). Therefore, plastics larger than $5 \mathrm{~mm}$, turn into particles smaller than $5 \mathrm{~mm}$, often called microplastics (MP), due to the aforementioned factors. MPs can also be released directly into the 
environment as micro-sized particles designed for various purposes (e.g. resin pellet, microbead, etc.). MPs were first reported in the Sargasso sea by (Carpenter and Smith, 1972). Since this first report, early studies have mainly focused on the marine and freshwater environments. It is now widely known that MPs now can be found in all ecosystems (including, air, water and soil), personal care products, table salt and seafood (Dehghani et al., 2017; Duis and Coors, 2016; Gündoğdu, 2018; Gündoğdu et al., 2021, 2020; Gündoğdu and Çevik, 2017; Lusher et al., 2018). Although most of the information we have about MP pollution today is from aquatic environments, in the last ten years, the number of MP studies that have focused on terrestrial environments has increased (Bläsing and Amelung, 2018; Büks and Kaupenjohann, 2020; Schell et al., 2021). Even with this increase, little is still known about the abundance and impact of MPs in soils, and in particular, within agricultural settings.

The use of plastics in agriculture has increased significantly in recent years (Maraveas, 2020). Plasticulture practices are varied and for a multitude of purposes, including improving crop productivity, animal nutrition, water use, and reducing food losses. For example, mulching films are used in crop production to suppress weed growth, increase soil temperatures, reduce topsoil and nutrient losses, and reduce soil water evaporation after heavy rainfall (Adhikari et al., 2016; Li et al., 2021). These factors increase crop yields, extend the growing season, and reduce the need for irrigation as well as fertilizer and herbicide applications. However, plastic mulch films are also known to be a significant source of macro and microplastic pollution. Their widespread and long-term use, coupled with a lack of systematic collection and management, has led to their accumulation in the soil (Ren et al., 2021). Soil pollution caused by micro and nanoplastics is not limited to mulching films. Disposable irrigation pipes, fruit protection films, and empty agrochemical containers that are poorly managed and abandoned on farms also contribute to agricultural plastic pollution. Büks and Kaupenjohann (2020) state that soils, where plastic-containing agricultural applications are made, contain significant MP residues. The low-tunnel greenhouse plastic films are an important source of MP in arable soils (Huang et al., 2020). This thin-film type plastic (8-50 $\mu \mathrm{m}$ thick polyethylene) is thought to be unaffected by biodegradation processes and therefore, limiting entry to the soil (Qi et al., 2020a; Steinmetz et al., 2016). The use of sewage sludge as a source of organic matter and effluent water for irrigation risks mixing micro and nanoplastics into agricultural soils, as all wastewater treatment plants do not effectively remove these particles. MPs in soil threaten human and ecosystem health due to their potential to bioaccumulate in the food web. MPs also risk carrying other pollutants such as pesticides that enter the food chain and harm human and environmental health. MP accumulation in agricultural soil affects soil water holding capacity, soil aggregation, performance, and composition of soil microbial community, soil fauna, and flora which can affect agricultural productivity (Büks et al., 2020; de Souza Machado et al., 2018; Fei et al., 2020; Lehmann et al., 2019; Rillig et al., 2019). MPs also affect organisms that live within and are reliant on the soil environment including earthworms, snails and soil nematodes (Lei et al., 2018; Song et al., 2019; Wang et al., 2019).

Plastic applications in agricultural activities are escalating in Turkey as well as all over the world. According to PAGEV (2020), 382 thousand tons of plastic produced by Turkey as of 2020, is used for agricultural purposes, with the primary application types being greenhouse and disposable drip irrigation 
piping. Turkey ranks in the top four in the world in greenhouse cultivation, and ranks second in Europe after Spain (Tüzel et al., 2020). Turkey's total greenhouse area has reached 77209.1 ha as of 2018. The low plastic tunnel application is $27.36 \%$ of the total greenhouse area (Tüzel et al., 2020). It is worth noting that plastic material in greenhouse applications is relatively high, especially for low tunnel applications. Although there is not enough data, it can be proposed that disposable drip irrigation pipe applications are also increasing in parallel with greenhouse cover applications. This is the first study to quantify MPs from greenhouse covers and irrigation piping conducted on agricultural soils in Turkey. The purpose of this study was to investigate the abundance of MPs in agricultural soils, specifically those that originated from greenhouse cover plastics and disposable drip irrigation pipes.

This study aims to investigate the following hypotheses: both greenhouse films and disposable irrigation pipes (GFSUP) usage causes MP pollution in the soils; removal of plastics after use affects both the number and the size of MPs originated from GFSUP in the soil. The results aim to guide farmers and decision-makers in better managing the MP pollution in the fields and further the understanding of the behavior of plastics in GFSUP applied agricultural soils.

\section{Materials And Methods}

\section{Study Area}

The sampling area is the agricultural lands in the Adana/Karataş region of the Lower Seyhan Plain (LSP) where the most intensive plastic-use agricultural activities are carried out. LSP, which is an important region of Çukurova Delta, is an area of 210000 ha, bounded by the Taurus Mountains in the north, the Berdan River in the west, the Mediterranean Sea in the south, and the Ceyhan River in the east. (Yeler et al., 2017) reported that the agricultural product pattern in LSP is wheat in winter and watermelon, corn, cotton, vegetable, and soybean farming in summer. They also noted that it has an important place in citrus production throughout Turkey. This study selected ten different sampling locations where no crops have been planted yet in the Adana/Karataş region; soil samples were taken from these locations in triplicate (Fig.1; Table 1). These sites represent different land and plastic uses, including those that do not use plastic at all. It was noted during an initial field survey prior to sampling that the use of sewage sludge is not common for these areas.

\section{Sample Preparation and Microplastic Extraction}

Soil sampling was carried out by combining the soils taken with a steel shovel from 10 randomly determined points close to the midpoint of the field. Samples were taken from the topsoil ( $5 \mathrm{~cm}$ depth) and blended together to make them homogenous. Subsequently, $3 \times 1 \mathrm{~kg}$ of soil was taken from this blend and transferred to glass jars. As a result, three one $\mathrm{kg}$ soil samples were taken from each field. As this study was targeting specific sources of microplastic, i.e. greenhouse covers and irrigation piping, the need to control for procedural contamination from the analysts clothing or equipment during sampling and processing was not necessary as any microplastics from other sources were eliminated and not counted. Care was taken though to not cross-contaminate samples between field sites by washing 
equipment between sampling sites, ensuring the glass jars were tightly closed and keeping samples apart in the laboratory.

Samples were brought to the laboratory, weighed and passed through a stainless steel sieve (Kalyen Co. Istanbul/Turkey) with a $5 \mathrm{~mm}$ mesh size to remove particles larger than $5 \mathrm{~mm}$ in size (the upper limit for MPs). Then, the jars containing the sieved material were placed in an oven set at $40{ }^{\circ} \mathrm{C}$ overnight. After the water in the samples had evaporated, they were removed from the oven and weighed again. The samples were then transferred to sterilized glass jars of 5 liters, and ultrapure water was added to $1 \mathrm{~cm}$ above the soil. The samples were then left overnight until the soil was fully in solution which eliminated the aggregation caused by the soil structure. All equipment was washed between samples to prevent cross-contamination.

After the whole sample had become a solution, 4 molars Nal (with a density of approximately $1.6 \mathrm{~g} / \mathrm{ml}$ ) was added to the sample (3-5 cm above), stirred with a glass rod and left overnight to be able to perform the density separation. After the density separation, the floating materials were passed through a 55micron mesh size sieve. Then, the material remaining on the sieve was placed in a sterile glass jar, and Fenton reagent (organic matter digestion solution) was added to digest all the organic matter (Hurley et al., 2018; Tagg et al., 2017). The mixture was heated on a hot plate set at $40^{\circ} \mathrm{C}$ until the organic matter disappeared completely. After all the organic matter was digested, the solution was kept in a closed fume hood for one day to cool, then, the solutions were passed through a 55-micron sieve again, and the remained materials were transferred onto a 0.45-micron pore size membrane filter (Millipore S-Pack HAWG047S6) with the help of a glass filtration system connected to a vacuum pump. The filter paper was transferred into a closed glass petri dish and preserved for microscopic analysis. Filter papers were examined under an Olympus SZX 16 microscope with Canon EOS 450D camera at magnifications between $0.7 x$ and $30 x$. Known samples of plastic from the greenhouse covers and disposable drip irrigation pipes were recovered as controls for comparison purposes to enable MPs from these sources to be easily identified in the soil samples. Transparent film plastics originating from greenhouse cover plastics and black and hard MPs originating from disposable drip irrigation pipes were counted, photographed, and recorded. Measurements of the photographed particles were also carried out using the Feret's diameter as part of the ImageJ v1.50i program. Whether the particles were plastic or not was checked with a hot needle after the necessary measurements were made.

MP concentrations are given as MPs $/ \mathrm{kg} \pm$ standard error. In the statistical analysis, the KolmogorovSmirnov test was applied to determine whether the number of MPs data fit a normal distribution and Levene's homogeneity of variance test were applied to the data, and if necessary, the natural logarithm transformation was used to ensure the data fit the normal distribution. A one-way ANOVA was used to determine whether the amount of MP was different between locations. An independent samples t-test was used to determine the difference in number and size of MPs between greenhouse films and drip irrigation pipes. Statistical analyzes were performed using SPSS v25 (IBM, Chicago, IL. USA), and Tableau v.20 was used to visualize the data 


\section{Results}

\section{Microplastic concentration}

During the field studies carried out in September 2020, 10 different field sites were visited. Three of the sites did not have any plastic application, and seven were fields with both greenhouse cover plastic and disposable drip irrigation applications (Table 2). As shown from Table 2, most farmers do not collect the plastics they use, and of the farmers who use plastics, most have used them for more than 5 years. Watermelon, tomato, pepper and peanut farm types were farms that have used plastics for longer than 5 years.

The mean MPs from greenhouse covers and irrigation pipes was $11.13 \pm 2.31 \mathrm{MPs} / \mathrm{kg}$ dry soil across all sampling locations. According to the individual regions sampled, the highest MP amount was determined in the Bahçe-4 location with $32.0 \pm 14.36 \mathrm{MPs} / \mathrm{kg}$, and the lowest MP amount was determined in the Karataş-1 location with $0.3 \pm 0.3 \mathrm{MPs} / \mathrm{kg}$. In the Karataş-2 location, however, no microplastics originating from greenhouse cover plastic and disposable drip irrigation pipes were encountered (Figure 2; Figure 3). Since there is no plastic application in Karataş-1 and Karataş-2 locations, the absence or small amounts of MP was expected. Similarly, a very low amount of MP was found in the Bahçe-2 location $(0.67 \pm 0.6$ $\mathrm{MPs} / \mathrm{kg}$ ), which is another location where there was no plastic application. However, it is thought that the detection of MPs in this area, albeit at a low amount, may be related to the application of plastics in neighboring fields. Therefore, it is possible to propose that the type of agriculture in which plastic application is applied causes a significant amount of MP residue to be accumulated in the fields. Using a one-way ANOVA test, it was determined that there was a significant difference between the locations in terms of MP amounts (Table 3; $p<0.05$ ).

In terms of their sources, it was determined that $13 \%$ of MPs were from disposable drip irrigation pipes, and $87 \%$ from greenhouse plastics (Figure 4). The difference between the MP amounts from the disposable pipes and greenhouse cover plastics in all locations was statistically significant $(p<0.05)$. Size distributions of MPs were between $0.11 \mathrm{~mm}$ and $5.9 \mathrm{~mm}$, with an average size of $3.28 \pm 0.08 \mathrm{~mm}$, and did not show a statistically significant difference according to their types ( $p>0.05)$. However, the size distributions according to regions showed a significant difference $(p<0.05)$. The mean size of MPs originating from disposable greenhouse plastics was $3.29 \pm 0.09 \mathrm{~mm}$, and the average size of MPs originating from disposable drip irrigation pipes was $3.17 \pm 0.22 \mathrm{~mm}$ (Figure 4).

The amount of MPs were compared between sites which removed greenhouse plastic and disposable pipe plastic from fields and where they were not. It was determined that MP concentration is negatively correlated with the removal of plastics in the field (Figure 5).

Table 3. Mean, minimum, maximum values (items/kg dry soil), and standard errors of microplastics. The uppercase symbols are based on the DUNCAN multiple comparison tests performed to determine the difference. 


\begin{tabular}{|c|c|c|c|c|}
\hline Location & Mean & Std. Error & Minimum & Maximum \\
\hline Ataköy-1 ${ }^{a, b}$ & 23.00 & 3.46 & 17.00 & 29.00 \\
\hline Ataköy-2 $2^{b, c}$ & 8.00 & 3.61 & 3.00 & 15.00 \\
\hline Ataköy-3 $3^{b, c}$ & 12.00 & 3.21 & 7.00 & 18.00 \\
\hline Bahçe-1 $1^{b, c}$ & 9.33 & 6.17 & 1.00 & 21.00 \\
\hline Bahçe-2 ${ }^{c}$ & 0.67 & 0.67 & 1.00 & 2.00 \\
\hline Bahçe-3 $3^{b, c}$ & 11.67 & 3.84 & 4.00 & 16.00 \\
\hline Bahçe-4 ${ }^{a}$ & 32.00 & 14.36 & 10.00 & 59.00 \\
\hline Karataş-1 ${ }^{c}$ & 0.33 & 0.33 & 0.00 & 1.00 \\
\hline Karataş-2 ${ }^{c}$ & 0.00 & 0.00 & 0.00 & 0.00 \\
\hline Tuzla- $1^{b, c}$ & 13.33 & 2.67 & 8.00 & 16.00 \\
\hline Total & 11.13 & 2.31 & 0.00 & 59.00 \\
\hline
\end{tabular}

The number of MPs in the fields of those whose landowners stated that they collected both types of plastics was less than those who stated that they only removed the pipes and those who said that they did not remove at all. The MP concentration in the fields of those who remove only the pipes and those who do not remove any of them were similar to each other. This raises the possibility that the greenhouse plastics are the main cause of MP pollution in these environments (Figure 5). It has been determined that the sizes of MPs are relatively smaller when there is no removal of used plastics compared to the sites that plastics removed (Figure 5, lower panel). Although the sizes of the MPs in the fields where only the pipes are removed are relatively smaller than in the case of no removal, there is no significant difference. This reveals that not removing plastics from the field leads to a decrease in MP size seen.

\section{Discussion}

This study determined the MP concentrations of agricultural soils in the Adana/Karataş region, where low tunnel cover greenhouse and disposable drip irrigation pipe were applied. The results were compared with the MP contents in agricultural soils that did not apply disposable drip irrigation pipe and low tunnel cover greenhouse in the same region. It has been shown that both applications create MP pollution in agricultural areas. The possibility of MP pollution from other sources (other agricultural plastic applications, vehicle tires, wind and rain from other sources) was not considered, with the level of MP pollution caused by the relevant applications in agricultural areas being focussed on and quantified in a 
simple manner. In this study, an average of $11.13 \pm 2.31 \mathrm{MPs} / \mathrm{kg}$ MP concentration was found. This value is considerably lower than the MP amounts of $78 \pm 12.9 \mathrm{MPs} / \mathrm{kg}$ and $1444 \pm 986 \mathrm{MPs} / \mathrm{kg}$, respectively, reported for agricultural soils in China by (Liu et al., 2018; Yu et al., 2021). It is thought that the main reason for this situation is the consideration of MPs included in agricultural areas from other sources in both studies. Therefore, the MP pollution level of the agricultural areas considered in this study may be much higher if all MP sources were considered. More detailed MP pollution profile research is required to understand this fully.

Sources of MPs in agricultural areas can be listed as wastewater treatment sludge, compost, irrigation with wastewater, surface runoff, atmospheric deposition, and plastic use in agricultural production (Bläsing and Amelung, 2018; He et al., 2018). Previous studies have shown that wastewater treatment sludge (Corradini et al., 2019; Nizzetto et al., 2016; Zhang and Liu, 2018), external inputs such as organic fertilizers made from biological wastes (Weithmann et al., 2018) and irrigation wastewater use (Zhang and Liu, 2018) make significant contributions to MP pollution in agricultural soil. Thus, the agro-soil ecosystem is recognized as a critical accumulation area of MPs (Boots et al., 2019; Qi et al., 2020b).

Plastic greenhouses covered $4270 \mathrm{~km}^{2}$ of agricultural land in Europe in 2010 (Steinmetz et al., 2016) and has achieved an annual growth rate of 5-10\% worldwide in recent years (He et al., 2018). Greenhouse cover plastics have been widely used in greenhouses and soil mulching of farmland throughout the world since the 1970s. Plastics in use in agricultural areas or unmanaged plastic waste can be broken down into MPs by physical degradation, chemical aging, and biodegradation in agricultural environments ( $\mathrm{Ng}$ et al., 2018; Rezaei et al., 2019). Therefore, agroecosystems with the widespread use of plastic can also be considered as continuous MP production areas due to the repeated use of plastics used for agricultural purposes every year. The duration of stay of the plastic greenhouses in the fields is positively correlated with the degradation level. The degradation of PE plastic by ultraviolet (UV) exposure, abrasion by soil particles, and wind erosion in field conditions have been expressed in previous studies (Rezaei et al., 2019; Song et al., 2017). For this reason, the fact that it is not collected back from the soil after the use of greenhouse cultivation or drip irrigation, is considered as an important source for the production of MPs in the soil, as revealed in this study. It was observed in this study that disposable irrigation pipes and low tunnel cover plastics were randomly found around the fields, all of which are potential sources of MPs if not collected. Large amounts of MPs resulting from the widespread use of plastic film also bring some pollution hazards (Jambeck et al., 2015). MPs from greenhouses covering plastics may reduce soil porosity and air circulation, alter microbial communities, and lead to low soil fertility, with consequent effects on crop seed germination and seedling growth (Kasirajan and Ngouajio, 2012). In the personal communication with the farmers during the sampling, the farmers stated that the plastic remaining in the field poses a threat to peanut planting, especially after watermelon planting, as the peanuts cannot grow as they get caught in the plastic residues. (Cuello et al., 2015) found that plastic greenhouse covering films significantly reduce soil organic matter content and increase greenhouse gas emissions. Also, several studies show that crop yields decrease when plastic film residues are found in the soil at rates of up to $58.5 \mathrm{~kg} / \mathrm{ha}$ (Li et al., 2014; Selonen et al., 2019). Pieces of the plastic film have also been found to 
accumulate pesticides and other toxins found in the soil (Ramos et al., 2015). In addition, plastic film residue can reduce soil microbial biomass and microbial activity, depending on the type and color of the film (Moreno and Moreno, 2008). Plastic film residues in the soil can also cause potentially carcinogenic and mutagenic phthalate acid esters (PAEs) to enter the soil (Fu and Du, 2011; Wang et al., 2015).

\section{Conclusion}

This study has demonstrated that agricultural soils in the Adana Karataş region have significant MP pollution due to plasticulture application. This pollution level is highly correlated with whether disposable drip irrigation pipes and low tunnel greenhouse covers, which are the source of polluting MPs, are removed from the site. It has been shown that the removal of plastics from the soil after use, albeit at a limited level, significantly reduces the amount of MPs in the soil. This indicates that an effective plastic collection activity can cause a significant reduction in the amount of MPs in agricultural soils where plastic culture is applied. Therefore, decision makers need to take adequate measures to reduce the MP pollution load in the soil by coordinating with all stakeholders for the regular and effective post-use collection of these plastics. The collection of plastics after use also has a significant effect on the size of MPs in the soil. Accordingly, the fact that the dimensions of MPs are relatively larger in agricultural areas where plastics are collected reveals that the plastics have yet to break down into smaller sizes. This poses a severe risk for both the environment, animal, and human health. During the field visits, it is observed that plastics can be transported to further points with environmental factors such as rain and wind. In this context, the use of plastic in agricultural production should be controlled with strict protocols, and management plans should be developed to include the collection of used plastics.

\section{Declarations}

\section{Acknowledgements}

The author also wish to thank Umut Işık for his support sampling campaign.

\section{Funding}

This study was supported by the Cukurova University Scientific Project Unit (Project numbers FYL-202012847 and FBA-2021-13403).

\section{Author information}

\section{Affiliations}

Cukurova University, Faculty of Agriculture, Department Agricuştural Structures and Irrigation, 01330 Adana, Turkey

Rezan Gündoğdu \& Derya Önder 
Cukurova University, Faculty of Fisheries, Department of Basic Sciences, 01330 Adana, Turkey

Sedat Gündoğdu

Staffordshire University, Criminal Justice and Forensic Science Department UK

Claire Gwinnett

\section{Contributions}

Rezan Gündoğdu: Conceptualization; Data curation; Formal Analysis; Investigation; Methodology; Project administration; Resources; Software; Validation; Visualization; Writing - original draft; Writing - review \& editing, Derya Önder: Conceptualization; Data curation; Investigation; Project administration, Writing review \& editing, Sedat Gündoğdu Data curation; Formal Analysis; Investigation; Methodology; Software; Validation; Visualization; Writing - original draft; Writing - review \& editing, Claire Gwinnett: Methodology; Writing - original draft; Writing - review \& editing

\section{Corresponding author}

Correspondence to Rezan Gündoğdu: rezan.erdogmus@gmail.com

\section{Ethics declarations}

Ethics approval and consent to participate

Not applicable

\section{Consent for publication}

Not applicable

\section{Competing interests}

The authors declare no competing interests.

\section{References}

1. Adhikari, R., Bristow, K.L., Casey, P.S., Freischmidt, G., Hornbuckle, J.W., Adhikari, B., 2016. Preformed and sprayable polymeric mulch film to improve agricultural water use efficiency. Agric. Water Manag. 169, 1-13. https://doi.org/10.1016/j.agwat.2016.02.006

2. Barnes, D.K.A., Galgani, F., Thompson, R.C., Barlaz, M., 2009. Accumulation and fragmentation of plastic debris in global environments. Philos Trans R Soc L. B Biol Sci 364, 1985-1998. https://doi.org/10.1098/rstb.2008.0205 
3. Bläsing, M., Amelung, W., 2018. Plastics in soil: Analytical methods and possible sources. Sci. Total Environ. 612, 422-435. https://doi.org/10.1016/j.scitotenv.2017.08.086

4. Boots, B., Russell, C.W., Green, D.S., 2019. Effects of Microplastics in Soil Ecosystems: Above and below Ground. Environ. Sci. Technol. 53, 11496-11506. https://doi.org/10.1021/acs.est.9b03304

5. Büks, F., Kaupenjohann, M., 2020. Global concentrations of microplastic in soils, a review. SOIL Discuss. 1-26. https://doi.org/10.5194/soil-2020-50

6. Büks, F., Loes Van Schaik, N., Kaupenjohann, M., 2020. What do we know about how the terrestrial multicellular soil fauna reacts to microplastic? Soil 6, 245-267. https://doi.org/10.5194/soil-6-2452020

7. Carpenter, E.J., Smith, K.L., 1972. Plastics on the Sargasso sea surface. Science (80-. ). 175, 12401241. https://doi.org/10.1126/science.175.4027.1240

8. Corradini, F., Meza, P., Eguiluz, R., Casado, F., Huerta-Lwanga, E., Geissen, V., 2019. Evidence of microplastic accumulation in agricultural soils from sewage sludge disposal. Sci. Total Environ. 671, 411-420. https://doi.org/10.1016/j.scitotenv.2019.03.368

9. Cuello, J.P., Hwang, H.Y., Gutierrez, J., Kim, S.Y., Kim, P.J., 2015. Impact of plastic film mulching on increasing greenhouse gas emissions in temperate upland soil during maize cultivation. Appl. Soil Ecol. 91, 48-57. https://doi.org/10.1016/j.apsoil.2015.02.007

10. de Souza Machado, A.A.S., Lau, C.W., Till, J., Kloas, W., Lehmann, A., Becker, R., Rillig, M.C., 2018. Impacts of microplastics on the soil biophysical environment. Environ. Sci. Technol. acs.est.8b02212. https://doi.org/10.1021/acs.est.8b02212

11. Dehghani, S., Moore, F., Akhbarizadeh, R., 2017. Microplastic pollution in deposited urban dust, Tehran metropolis, Iran. Environ. Sci. Pollut. Res. 24, 20360-20371. https://doi.org/10.1007/s11356017-9674-1

12. Duis, K., Coors, A., 2016. Microplastics in the aquatic and terrestrial environment: sources (with a specific focus on personal care products), fate and effects. Environ. Sci. Eur. 28, 1-25. https://doi.org/10.1186/s12302-015-0069-y

13. Fei, Y., Huang, S., Zhang, H., Tong, Y., Wen, D., Xia, X., Wang, H., Luo, Y., Barceló, D., 2020. Response of soil enzyme activities and bacterial communities to the accumulation of microplastics in an acid cropped soil. Sci. Total Environ. 707, 135634. https://doi.org/10.1016/j.scitotenv.2019.135634

14. Fu, X., Du, Q., 2011. Uptake of di-(2-ethylhexyl) phthalate of vegetables from plastic film greenhouses. J. Agric. Food Chem. 59, 11585-11588. https://doi.org/10.1021/jf203502e

15. Gündoğdu, S., 2018. Contamination of table salts from Turkey with microplastics. Food Addit. Contam. - Part A Chem. Anal. Control. Expo. Risk Assess. 35, 1006-1014. https://doi.org/10.1080/19440049.2018.1447694

16. Gündoğdu, S., Çevik, C., 2017. Micro- and mesoplastics in Northeast Levantine coast of Turkey: The preliminary results from surface samples. Mar. Pollut. Bull. 118, 341-347. https://doi.org/10.1016/j.marpolbul.2017.03.002 
17. Gündoğdu, S., Çevik, C., Temiz Ataş, N., 2020. Occurrence of microplastics in the gastrointestinal tracts of some edible fish speciealong the Turkish coast. Turkish J. Zool. 44, 312-323. https://doi.org/10.3906/zoo-2003-49

18. Gündoğdu, S., Eroldoğan, O.T., Evliyaoğlu, E., Turchini, G.M., Wu, X.G., 2021. Fish out, plastic in: Global pattern of plastics in commercial fishmeal. Aquaculture 534, 736316. https://doi.org/10.1016/j.aquaculture.2020.736316

19. Gündoğdu, S., Walker, T.R., 2021. Why Turkey should not import plastic waste pollution from developed countries? Mar. Pollut. Bull. 171, 112772.

20. He, D., Luo, Y., Lu, S., Liu, M., Song, Y., Lei, L., 2018. Microplastics in soils: analytical methods, pollution characteristics and ecological risks. TrAC Trends Anal. Chem. 109, 163-172. https://doi.org/10.1016/J.TRAC.2018.10.006

21. Huang, Y., Liu, Q., Jia, W., Yan, C., Wang, J., 2020. Agricultural plastic mulching as a source of microplastics in the terrestrial environment. Environ. Pollut. 260, 114096.

https://doi.org/10.1016/j.envpol.2020.114096

22. Hurley, R.R., Lusher, A.L., Olsen, M., Nizzetto, L., 2018. Validation of a Method for Extracting Microplastics from Complex, Organic-Rich, Environmental Matrices. Environ. Sci. Technol. 52, 74097417. https://doi.org/10.1021/acs.est.8b01517

23. Jambeck, J.R., Geyer, R., Wilcox, C., Siegler, T.R., Perryman, M., Andrady, A., Narayan, R., Law, K.L., 2015. Plastic waste inputs from land into the ocean. Science (80-. ). 347, 768-771. https://doi.org/10.1126/science.1260352

24. Kasirajan, S., Ngouajio, M., 2012. Polyethylene and biodegradable mulches for agricultural applications: A review. Agron. Sustain. Dev. 32, 501-529. https://doi.org/10.1007/s13593-011-00683

25. Lehmann, A., Fitschen, K., Rillig, M.C., 2019. Abiotic and biotic factors influencing the effect of microplastic on soil aggregation. Soil Syst. 3, 1-8. https://doi.org/10.3390/soilsystems3010021

26. Lei, L., Liu, M., Song, Y., Lu, S., Hu, J., Cao, C., Xie, B., Shi, H., He, D., 2018. Polystyrene (nano)microplastics cause size-dependent neurotoxicity, oxidative damage and other adverse effects in Caenorhabditis elegans. Environ. Sci. Nano 5, 2009-2020. https://doi.org/10.1039/c8en00412a

27. Li, C., Moore-Kucera, J., Lee, J., Corbin, A., Brodhagen, M., Miles, C., Inglis, D., 2014. Effects of biodegradable mulch on soil quality. Appl. Soil Ecol. 79, 59-69. https://doi.org/10.1016/j.apsoil.2014.02.012

28. Li, C., Sun, M., Xu, X., Zhang, L., 2021. Characteristics and influencing factors of mulch film use for pollution control in china: Microcosmic evidence from smallholder farmers. Resour. Conserv. Recycl. 164, 105222. https://doi.org/10.1016/j.resconrec.2020.105222

29. Liu, M., Lu, S., Song, Y., Lei, L., Hu, J., Lv, W., Zhou, W., Cao, C., Shi, H., Yang, X., He, D., 2018. Microplastic and mesoplastic pollution in farmland soils in suburbs of Shanghai, China. Environ. Pollut. 242, 855-862. https://doi.org/10.1016/j.envpol.2018.07.051 
30. Lusher, A.L., Hernandez-Milian, G., Berrow, S., Rogan, E., O'Connor, I., 2018. Incidence of marine debris in cetaceans stranded and bycaught in Ireland: Recent findings and a review of historical knowledge. Environ. Pollut. 232, 467-476. https://doi.org/10.1016/j.envpol.2017.09.070

31. Maraveas, C., 2020. Environmental sustainability of plastic in agriculture. Agric. 10, 1-15. https://doi.org/10.3390/agriculture10080310

32. Moreno, M.M., Moreno, A., 2008. Effect of different biodegradable and polyethylene mulches on soil properties and production in a tomato crop. Sci. Hortic. (Amsterdam). 116, 256-263. https://doi.org/10.1016/j.scienta.2008.01.007

33. Ng, E.L., Huerta Lwanga, E., Eldridge, S.M., Johnston, P., Hu, H.W., Geissen, V., Chen, D., 2018. An overview of microplastic and nanoplastic pollution in agroecosystems. Sci. Total Environ. 627, 1377-1388. https://doi.org/10.1016/J.SCITOTENV.2018.01.341

34. Nizzetto, L., Futter, M., Langaas, S., 2016. Are Agricultural Soils Dumps for Microplastics of Urban Origin? Environ. Sci. Technol. 50, 10777-10779. https://doi.org/10.1021/acs.est.6b04140

35. PAGEV, 2021. Türkiye Plastik Sektör İzleme Raporu 2020.

36. PlasticEurope, 2020. Plastics - the Facts 2020, PlasticEurope.

37. Qi, R., Jones, D.L., Li, Z., Liu, Q., Yan, C., 2020a. Behavior of microplastics and plastic film residues in the soil environment: A critical review. Sci. Total Environ. 703, 134722. https://doi.org/10.1016/j.scitotenv.2019.134722

38. Qi, R., Jones, D.L., Li, Z., Liu, Q., Yan, C., 2020b. Behavior of microplastics and plastic film residues in the soil environment: A critical review. Sci. Total Environ. https://doi.org/10.1016/j.scitotenv.2019.134722

39. Ren, S.Y., Kong, S.F., Ni, H.G., 2021. Contribution of mulch film to microplastics in agricultural soil and surface water in China. Environ. Pollut. 291, 118227. https://doi.org/10.1016/j.envpol.2021.118227

40. Rezaei, M., Riksen, M.J.P.M., Sirjani, E., Sameni, A., Geissen, V., 2019. Wind erosion as a driver for transport of light density microplastics. Sci. Total Environ. 669, 273-281. https://doi.org/10.1016/j.scitotenv.2019.02.382

41. Rillig, M.C., Lehmann, A., de Souza Machado, A.A., Yang, G., 2019. Microplastic effects on plants. New Phytol. 223, 1066-1070. https://doi.org/10.1111/nph.15794

42. Schell, T., Hurley, R., Nizzetto, L., Rico, A., Vighi, M., 2021. Spatio-temporal distribution of microplastics in a Mediterranean river catchment: The importance of wastewater as an environmental pathway. J. Hazard. Mater. 420, 126481. https://doi.org/10.1016/j.jhazmat.2021.126481

43. Selonen, S., Dolar, A., Jemec Kokalj, A., Skalar, T., Parramon Dolcet, L., Hurley, R., van Gestel, C.A.M., 2019. Exploring the impacts of plastics in soil - The effects of polyester textile fibers on soil invertebrates. Sci. Total Environ. 134451. https://doi.org/10.1016/J.SCITOTENV.2019.134451

44. Song, Y., Cao, C., Qiu, R., Hu, J., Liu, M., Lu, S., Shi, H., Raley-Susman, K.M., He, D., 2019. Uptake and adverse effects of polyethylene terephthalate microplastics fibers on terrestrial snails (Achatina 
fulica) after soil exposure. Environ. Pollut. 250, 447-455.

https://doi.org/10.1016/j.envpol.2019.04.066

45. Song, Y.K., Hong, S.H., Jang, M., Han, G.M., Jung, S.W., Shim, W.J., 2017. Combined Effects of UV Exposure Duration and Mechanical Abrasion on Microplastic Fragmentation by Polymer Type. Environ. Sci. Technol. 51, 4368-4376. https://doi.org/10.1021/acs.est.6b06155

46. Steinmetz, Z., Wollmann, C., Schaefer, M., Buchmann, C., David, J., Tröger, J., Muñoz, K., Frör, O., Schaumann, G.E., 2016. Plastic mulching in agriculture. Trading short-term agronomic benefits for long-term soil degradation? Sci. Total Environ. 550, 690-705.

https://doi.org/10.1016/j.scitotenv.2016.01.153

47. Tagg, A.S., Harrison, J.P., Ju-Nam, Y., Sapp, M., Bradley, E.L., Sinclair, C.J., Ojeda, J.J., 2017. Fenton's reagent for the rapid and efficient isolation of microplastics from wastewater. Chem. Commun. 53, 372-375. https://doi.org/10.1039/c6cc08798a

48. Tüzel, Y., Gül, A., Bahar, G., Sait, Ö., Filiz, E., 2020. Türkiye'de örtüaltı yetiştiriciliği ve yeni gelişmeler, in: Türkiye Ziraat Mühendisliği IX.Teknik Kongresi.

49. Wang, H.T., Ding, J., Xiong, C., Zhu, D., Li, G., Jia, X.Y., Zhu, Y.G., Xue, X.M., 2019. Exposure to microplastics lowers arsenic accumulation and alters gut bacterial communities of earthworm Metaphire californica. Environ. Pollut. 251, 110-116. https://doi.org/10.1016/j.envpol.2019.04.054

50. Wang, J., Chen, G., Christie, P., Zhang, M., Luo, Y., Teng, Y., 2015. Occurrence and risk assessment of phthalate esters (PAEs) in vegetables and soils of suburban plastic film greenhouses. Sci. Total Environ. 523, 129-137. https://doi.org/10.1016/j.scitotenv.2015.02.101

51. WWF, 2018. Out of the plastic trap: saving the Mediterranean from plastic pollution.

52. Yeler, O., Şatir, O., Berberoğlu, S., 2017. Object based classification of crop pattern using multitemporal satellite dataset in multi-cropped agricultural areas: Lower seyhan plane case study. Yuz. Yil Univ. J. Agric. Sci. 27, 1-9. https://doi.org/10.29133/yyutbd.305090

53. Yu, L., Zhang, J. Di, Liu, Y., Chen, L.Y., Tao, S., Liu, W.X., 2021. Distribution characteristics of microplastics in agricultural soils from the largest vegetable production base in China. Sci. Total Environ. 756, 143860. https://doi.org/10.1016/j.scitotenv.2020.143860

54. Zhang, G.S., Liu, Y.F., 2018. The distribution of microplastics in soil aggregate fractions in southwestern China. Sci. Total Environ. 642, 12-20. https://doi.org/10.1016/j.scitotenv.2018.06.004

\section{Tables}

Table 1. Characteristics of sampling locations. GF: Greenhouse coverage film, SUP: Disposable irrigation pipes 


\begin{tabular}{|lllll|}
\hline Location & Plastic Usage & Last yield & Plasticulture background & Removal \\
\hline Bahçe-1 & GF and SUP & Watermelon & $>10 \mathrm{yr}$ & Yes only pipes \\
\hline Bahçe-2 & None & Maize/Soy & - & - \\
\hline Bahçe-3 & GF and SUP & Watermelon & $>10 \mathrm{yr}$ & Yes \\
\hline Bahçe-4 & GF and SUP & Watermelon & $>5 \mathrm{yr}$ & No \\
\hline Karataş-1 & None & Wheat & - & - \\
\hline Karataş-2 & None & Cotton & - & - \\
\hline Ataköy-1 & GF & Maize & $5 \mathrm{years}$ ago & Yes only pipes \\
\hline Ataköy-2 & GF and SUP & Tomato/Watermelon & $>5 \mathrm{yr}$ & No \\
\hline Ataköy-3 & GF and SUP & Watermelon/Peanut & $<5 \mathrm{yr}$ & No \\
\hline Tuzla-1 & GF and SUP & Pepper & $>5 \mathrm{yr}$ & No \\
\hline
\end{tabular}

Table 2 is not available with this version

\section{Figures}

\section{Figure 1}

Location of the study area and soil sampling points in the fields 


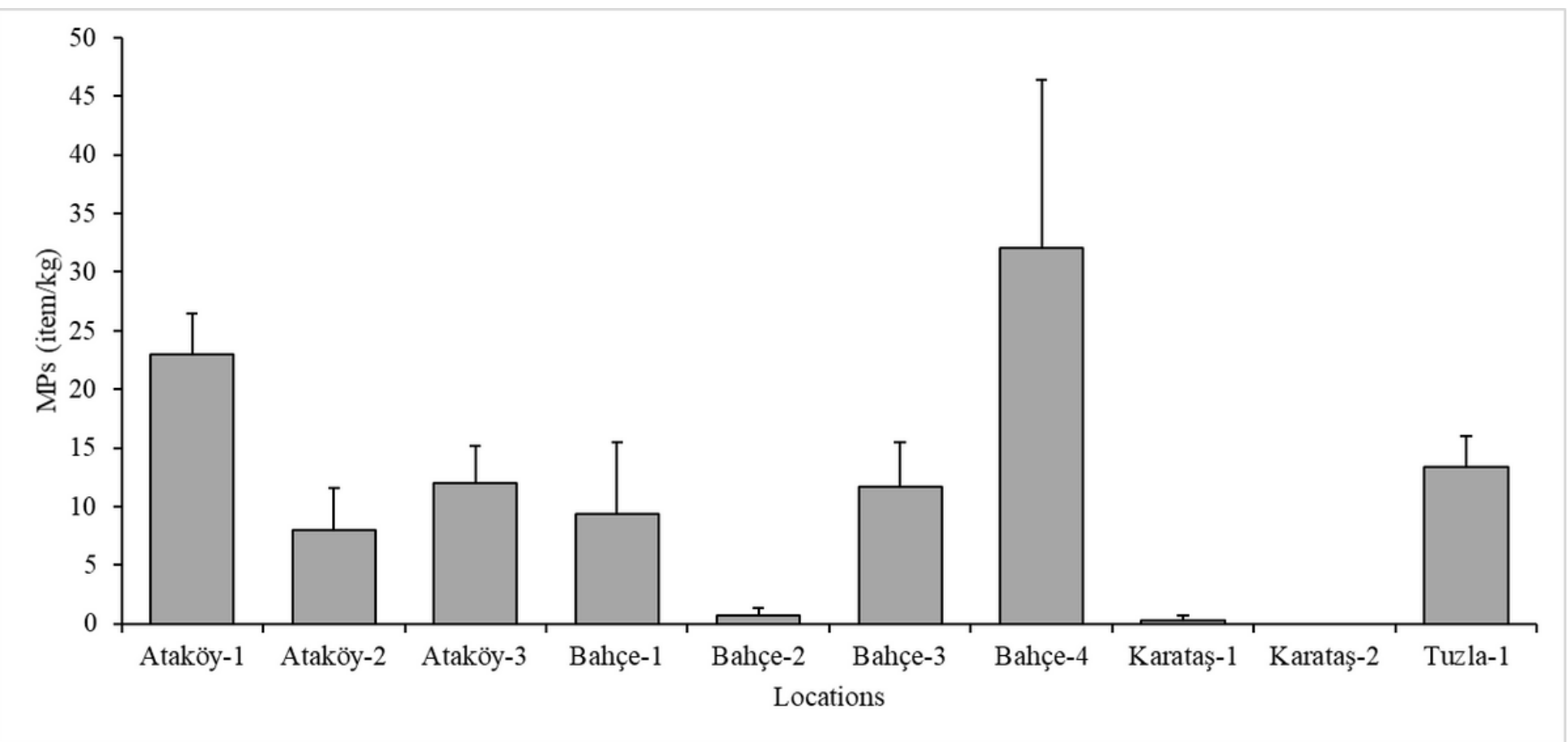

Figure 2

The number of microplastics by locations. Bars represent standard errors. 


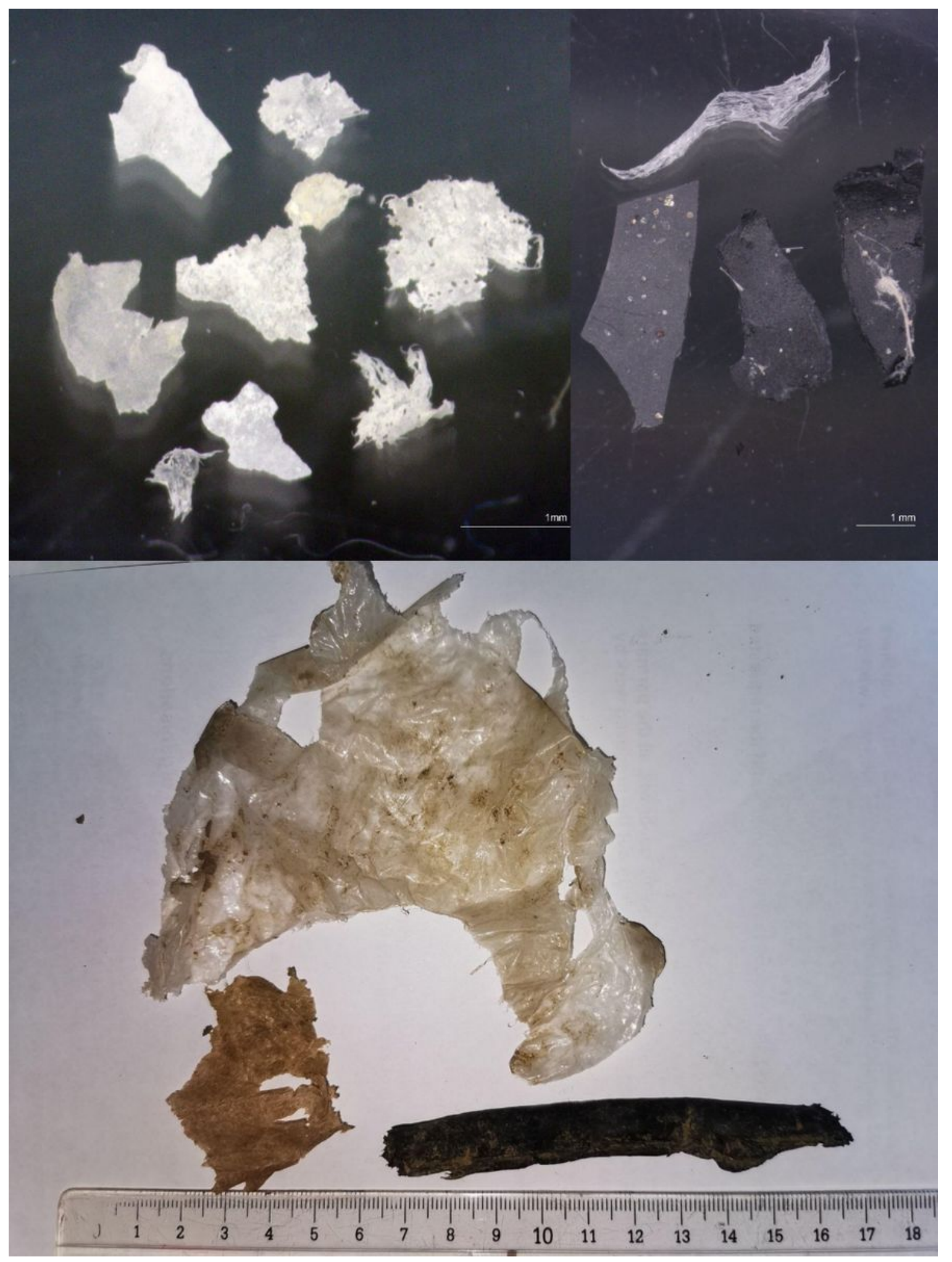

\section{Figure 3}

Upper panels: Microscopic images of microplastics were obtained from sampling locations. Transparent fragments are microplastics from greenhouse cover plastics and dark fragments are from drip irrigation pipes; Lower panel: larger residual plastics collected from the field for comparison. 
Figure 4

Size-frequency distributions of MPs by source
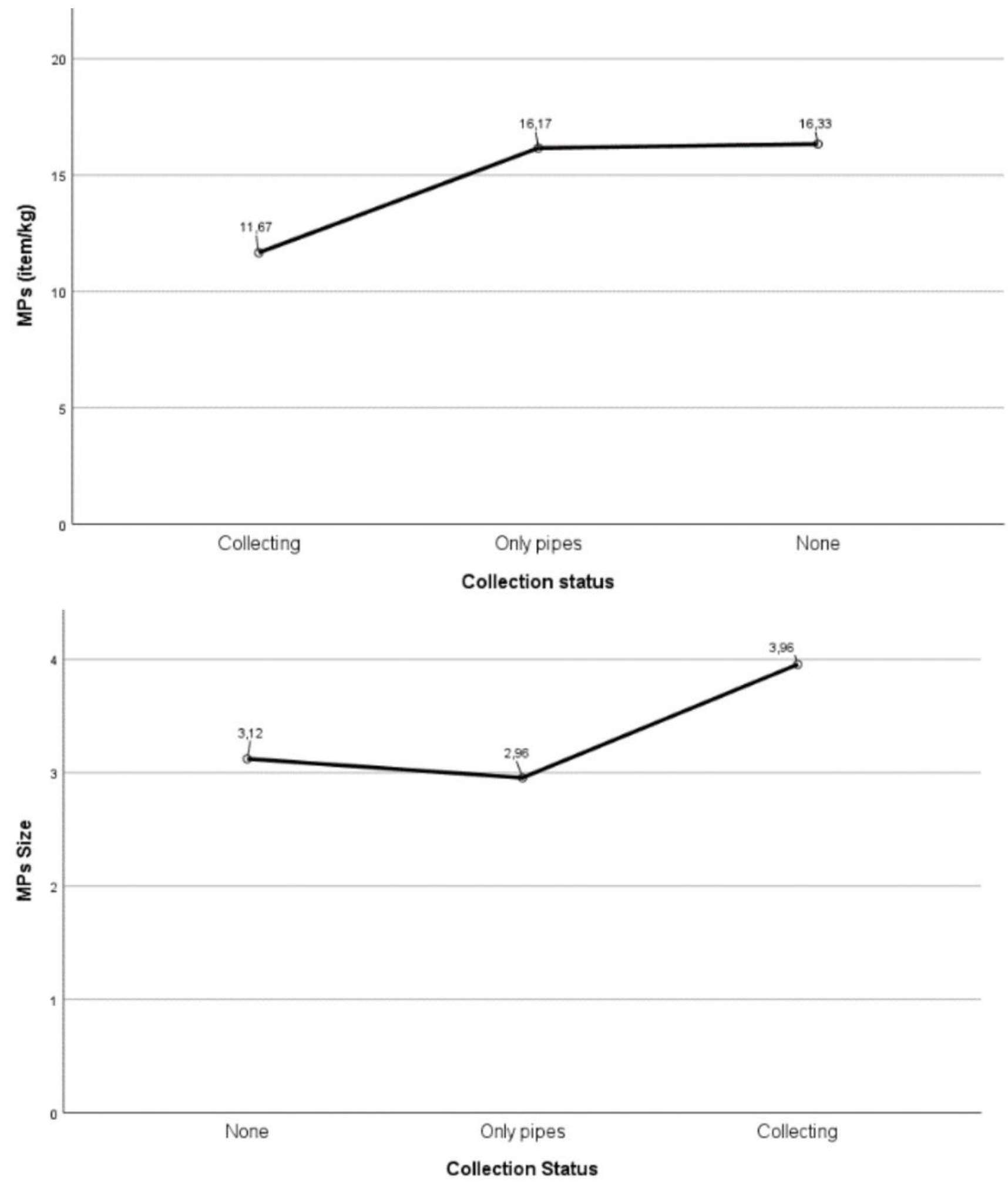

Figure 5

Page 18/19 
Number of microplastics (upper panel) and mean size of microplastics (lower panel) according to removal status 